\title{
Engaging Families in Lifestyle Changes through
}

\section{Social Networking}

\author{
NILUFAR BAGHAEI* ${ }^{*}$ STEPHEN KIMANI ${ }^{* *}$, JILL FREYNE $^{* *}$, EMILY BRINDAL ${ }^{* * *}$, \\ SHLOMO BERKOVSKY** $\&$ GREG SMITH*** \\ Tasmanian ICT Centre, CSIRO \\ GPO Box 1538 \\ Hobart, Tasmania 7001, Australia \\ ․ㅡbaghaei@unitec.ac.nz,
}

Food and Nutritional Sciences, CSIRO

GPO Box 10041

Adelaide, SA 5000, Australia

**** firstname.lastname@csiro.au

\begin{abstract}
Previous research has shown that providing family engagement and social support play important roles in weight management success, helping to achieve long-term lifestyle changes. Traditionally, the support provided by online health communities is primarily targeted at individuals and does not involve their families. We are proposing SOFA (SOcial FAmilies), a novel approach for engaging, motivating and persuading families to adopt a healthy lifestyle. SOFA is an online social network for families built on top of static health-related educational content. In this paper, we report the results of a live user study aimed at investigating how user profile representation and system assigned tasks influence users engagement with the system and change in their attitude towards healthy lifestyle. Our results show that representing family members as individuals increases the number of active family members as well as their retention, contribution and engagement with the network. The results further show that family-based social networks can have the potential to positively change the attitude of users towards healthy lifestyle.
\end{abstract}

Key words: Social Networks, User Engagement, Family, Health Care

\section{Introduction}

Poor diet and lifestyle choices are common risk factors for many diseases. Much research is being done on improving people's lifestyle and wellbeing, with a focus on weight management, exercise and other lifestyle intervention programs, including innovative use of information technologies to address the issue. Current weight management programs (e.g. WeightWatchers ${ }^{1}$ and JennyCraig ${ }^{2}$ ) have extended their service to provide online tools for planning, recording diet and exercise, and tracking goal progress. They also typically offer peer-support to individuals through areas such as bulletin boards and chat rooms. This support, however, is outside the family context and is targeted at individuals (Colineau et al., 2009),

http://www.weightwatchers.com/

http://www.jennycraig.com/ 
neglecting the role of families in the weight management process. Health care research has recognised the profound and supporting role of families in health promotion and disease prevention (Doherty, 2004; Doherty \& Campbell, 1998; Heimendinger at al., 2007). Furthermore, a family-centered approach to health care was found be more cost-effective than most of the approaches, which focus on individuals (Doherty \& Campbell, 1998). Clinical studies have also shown that social support has consistently been related to an increase in physical activity (Cohen, 2004).

Our goal in this work was to explore the effect of providing both family and social support through an online social networking system on engagement with the system and change in attitude toward healthy lifestyle. Within the social network we specifically wished to investigate the impact of two representations of family members, as individuals or as a family unit, and the presence of tasks. To this end, we designed, engineered and evaluated an online social system SOcial FAmilies (SOFA), which integrates a corpus of health-related educational content with a social networking system in order to expose users to healthy living knowledge and support in an online environment. The key novelty of our work is that it focuses on the family unit, investigating the effect of incorporating social technology to healthy living content in the family context.

We present a three week live user evaluation of SOFA conducted in July of 2009. The results obtained showed that representing families as individuals on the network increases the chances of multiple family members interacting with the system and results in significantly higher retention, contribution and engagement with the system. Moreover, our results suggest that family-based social networks have the potential to positively impact the health of family members.

The contributions of this work are 1) proposing a novel approach to address both family support and social support in helping individuals to adopt a healthy lifestyle, 2) evaluating the effect of different profile representations and tasks on user engagement with the social layer and educational content and 3) evaluating the effect of providing a social layer on users' change of attitude towards healthy living.

The paper is structured as follows. Section 2 describes the related work. Section 3 describes the details of SOFA, followed by an evaluation study described in Section 4. Section 5 presents the results. Finally, Section 6 concludes the paper by summarising the findings and outlining future research.

\section{Related Work}

In adopting a healthy lifestyle, some people suffer from lack of motivation to change their diet or exercise routines. Persuasive technologies, i.e., "interactive computing systems designed to change people's attributes or behaviors" (Fogg, 2003), can potentially support them and increase their engagement. A system that aims to encourage and support users in adopting a healthy lifestyle by changing their attitudes and/or behaviors is a good example of a persuasive technology.

Persuasive technologies are able to influence user behavior by applying principles that are recognized in the field of social psychology (Fogg, 2003). The following principles have been described in social psychology and persuasive technology literature (Oinas-Kukkonen \& Harjumaa, 2008; Fogg, 2003; Weiksner, Fogg \& Liu, 2008) - we refer to them as the social support framework for persuasive systems:

- Social learning: A user will be more motivated to perform a task if they can observe others performing a similar task.

- Normative influence: A system can provide a means for gathering together people who have the same goal in order to increase the likelihood that a person will adopt a target behavior.

- Self-expression: A user will be more motivated to perform a target behavior, if they are given ways to express themselves and are observed by others. 
- Social comparison: A user will be more motivated to perform a target behavior if they can compare their performance with that of others.

- Competition: A system can motivate users to adopt a target behavior if it provides means for competition.

- Recognition: A user will be more motivated to perform a task if they are offered recognition by other users.

The past few years have seen the explosive rise of web-based social networks, online social media sites and large-scale information sharing communities, which are all part of a Web 2.0 paradigm (Caverlee, Liu $\& W e b b, 2008$; McCown \& Nelson, 2009; Utz, 2010). The popularity of social networking websites has exploded with sites for recreation (Facebook ${ }^{3}$, Orkut ${ }^{4}$ and MySpace $^{5}$ ), career networking $\left(\right.$ LinkedIn $^{6}$ ), and enterprise use (Beehive (DiMicco et al., 2008)). Friendship social networks, such as Facebook with over 500 million active users (Facebook, 2010), have provided HCI and CSCW researchers with an opportunity to study the cues that result in behavior change (Rosenfeld, 2008). In contrast to traditional friendship driven networks, passion-centric networks (BodySpace ${ }^{7}$ ), which connect people with no previous off-line connections, have also come into existence. There, the connection depends on activities related to a shared passion rather than to off-line connections (Ploderer et al., 2008).

Research has been done on the persuasive aspects of online social networks (Fogg, 2003; Weiksner, Fogg \& Liu, 2008; Rosenfeld, 2008; Ploderer et al., 2008) and how they can provide the means for social learning. When integrated with educational content, social networks provide a basis for social learning. Being exposed to actions of others (both the contribution of content and the browsing habits), users can be made aware of the experiences of others on a similar journey to theirs.

There are some social networks in the context of health, such as TuDiabetes ${ }^{8}$, Leimeister \& Krcmar, 2005 and PatientsLikeMe ${ }^{9}$, where people might not necessarily know each other offline. They can share their experience, find similar patients and learn from others. This social support, however, is outside the family context and is designed for individuals. Relatively few health intervention studies incorporating a familybased component exist (McLean et al., 2003). Finding effective ways to actively engage the whole family is still an issue (Colineau et al., 2009). Research indicates that the family plays a fundamental role in the health of individuals, and that healthcare could be improved by supporting and strengthening the family role in health promotion and disease prevention (Doherty \& Campbell, 1998; Doherty, 2004). Research has also shown that there is an increased probability of an individual becoming obese if other family members are obese (Christakis \& Fowler, 2007). Jones et al. (2004) reports that patients diagnosed with type II diabetes might be more likely to change their diet and exercise patterns, if the family members supported these changes and if the family collectively followed through with a plan to establish a healthier lifestyle. A study intended at increasing fruit and vegetable consumption and physical activity in families showed that coaching together with family activities engaged families in the process of change and movement toward the achievement of their nutrition or physical activity goals (Heimendinger et al., 2007).

An online social networking system in itself might not be sufficient to sustain user engagement for an extensive period of time. Despite users' perceived usefulness of the support and resources provided by

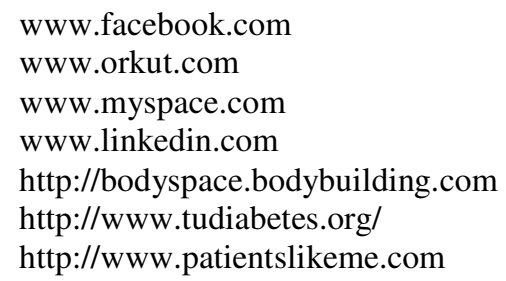


health-related online systems, user engagement and retention are often low (Leslie et al., 2005). Prespecified tasks can serve as entry points i.e., cues or structures that invite users to enter/use particular aspects of the system (Rogers et al., 2009). Entry points encourage users to enter and explore particular functionalities of the system, thus sustaining their engagement in the long-term. They are intended to minimise barriers to entry and to encourage users to use or explore the features supported by the system. Pre-specified tasks can also be useful to users in achieving their goals. They may direct users' effort to particular achievements, energise this effort over a period of time, and encourage the users to persist until their goals are met (Locke \& Latham, 2002).

Based on previous research indicating that social support can positively influence health (Cohen, 2004; Randell, Wilson \& Fitzpatrick, 2010) and on the growing popularity of online social networks, we feel that there is an opportunity for researchers and practitioners to leverage online social networks to support families in managing their lifestyle.

\section{SOFA - Online Social Networking for Families}

SOFA (Baghaei et al., 2009) is a family-oriented social network developed on top of health-related educational content, which aims to provide motivational and emotional support to influence families' attitude and behavior towards adopting a healthy lifestyle by exposing them to healthy living related content. Unlike existing social networks targeting individual users, SOFA aims to engage the whole family who would like to learn about healthy living or make any changes to their lifestyle.

The design of SOFA was informed by previous research on designing for families (Hutchinson et al., 2003), social and persuasive technologies, and by previous exploratory study (Colineau et al., 2009).

\subsection{RESEARCH AGENDA}

The aim of this study was to examine the effect of profile representation and system assigned tasks on user engagement with SOFA. We were also interested to know if increased engagement with the system would result in users' change of attitude towards healthy living. Three research questions are, therefore, investigated.

\section{- What balance needs to be struck in representing family members and the family unit in SOFA?}

The goal of our work is to include the entire family in lifestyle change. Previous research illustrates that the presence of family members leads to increased success, thus we facilitate family involvement in SOFA through family profiles. In this way one family member sets up the profile, which can be used by all members. Thus the barrier to entry for less motivated family members is low. Familybased profiles provide a level of anonymity, as they represent the families as family units on the network rather than as separate individuals. However, given that the motivations for social media include increased efficacy, reputation and sense of contribution through participating in the social network the presence of this family profile may reduce individuals' motivation to engage.

\section{- What is the effect of providing pre-specified tasks on interaction with SOFA?}

SOFA in itself might not be sufficient to sustain user engagement for an extensive period of time. Prespecified tasks may minimise barrier to entry and also expose users to the whole range of functionalities provided by SOFA. They may also help users to focus their effort and attention to particular achievements and encourage them to persist until they meet their goals. Pre-specified tasks are, therefore, likely to sustain user engagement with SOFA. We hypothesise that families who have been provided with pre-specified tasks have a higher level of engagement with SOFA than those who 
have not been given any pre-specified tasks.

- Will high engagement with the system result in changes in the attitude of users in relation to control over health?

Online social network users are likely to learn from the actions of others through activity feeds (e.g., blog messages, forum posts). Moreover, users might gain knowledge by directly accessing the healthrelated content. We hypothesise that exposure to other users' actions and the health-related content through the social networking system will provide users with the skills to change their lifestyle. We hypothesise that users who engage more with the system will gain greater knowledge, which could result in changes in attitude toward health control.

\subsection{SYSTEM DESCRIPTION}

The SOFA system has a static content component and a dynamic social networking component. The social networking component of SOFA consists of three core areas: a Home page, a user Profile page, and a discussion Forum.

A Profile page is a customizable page where family members can create their online identity. In order to investigate the questions relating to the impact of family and individual profiles, SOFA contains both. In the individual representation, each family member has their own profile and is seen on the network as an individual. In the family-based representation, each family has a single shared profile and interacts with others on the network as a family unit, rather than separate individuals (see Figure 1). Whether the profile page represents a family or an individual, it contains space for a profile photograph and personal details, as well as a blog, an activity diary, which can be used to report food intake and exercise, an image gallery, and a message board or Wall as it is known in SOFA.
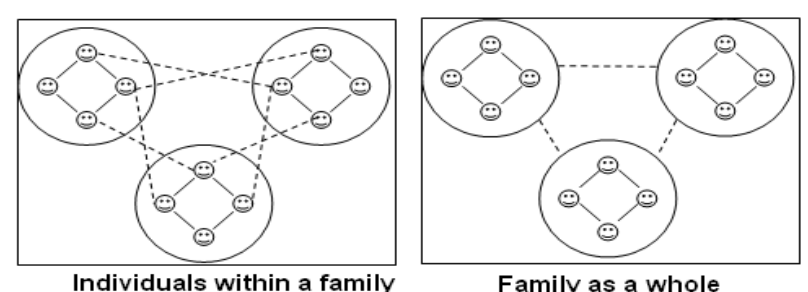

Figure 1: Family vs. Individual representation.

The Home page (Figure 2) provides users with summary information pertaining to activities of others. These include social networking activities such as friending, commenting, blogging, completing quizzes, and forum input, as well as the physical activities of users reported in the activity diaries. Unique to SOFA is the inclusion of browsing activity of community members within the healthy lifestyle content through an Activity Feed panel seen in Figure 3. The list of activities is hyperlinked, such that each activity is linked to the relevant page or component of SOFA and the profile of the user that performed the activity. Hence, through the activity feed users are made aware of popular content and can access pages browsed by other users in the community and their profile pages. 


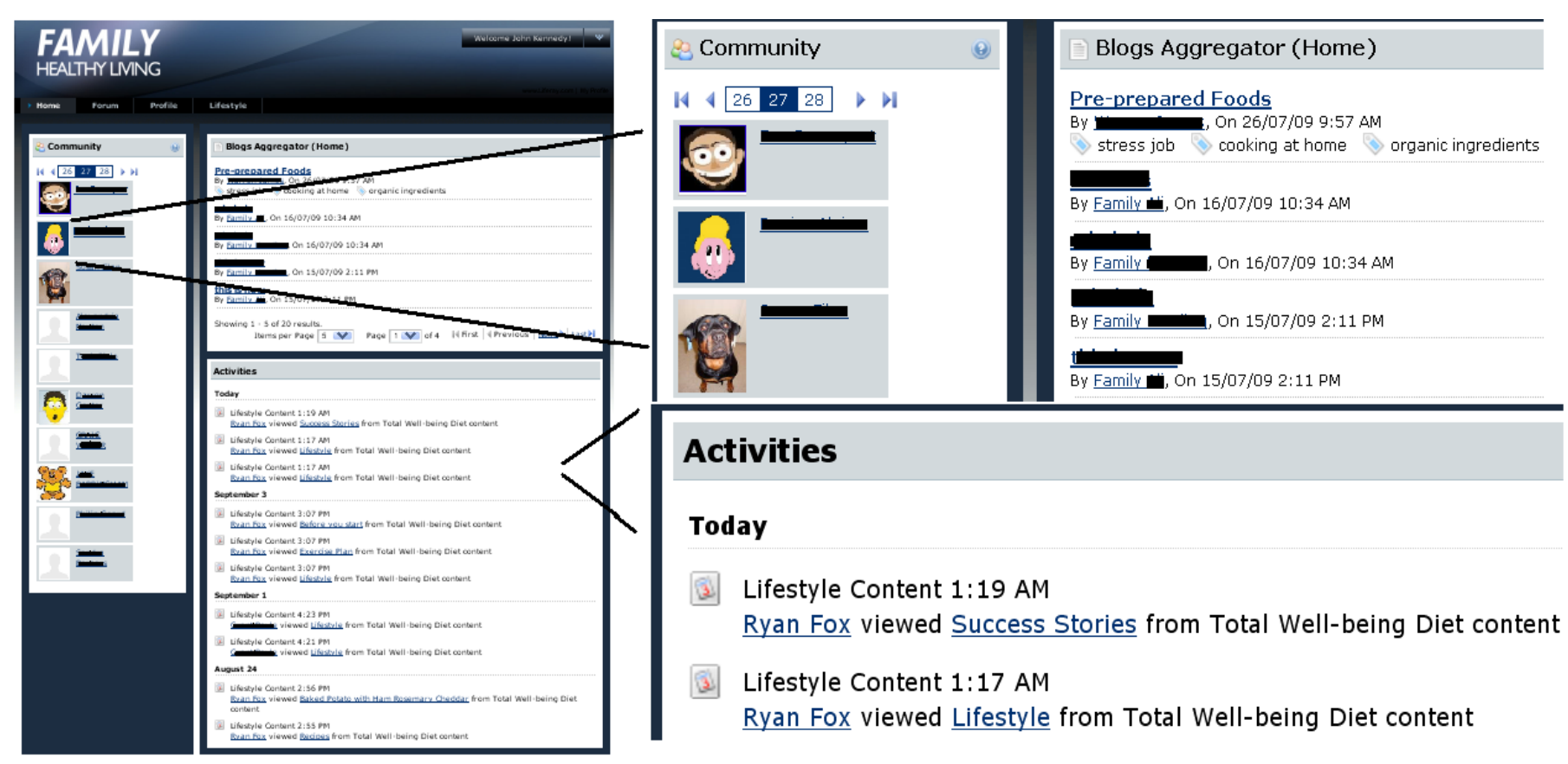

Figure 2. Screenshot of SOFA Home Page.

The Forum page provides users with a platform for social support from community members, where they can discuss/share information. It was the intention of the forum that the discussions should centre around healthy lifestyle and that users could ask questions, provide support, seek advice and discuss ideas and thoughts with the community at large. We seeded the forum with sample relevant threads to encourage this. The forum was monitored by a system administrator and by domain experts, who answered specific health, exercise and nutrition related questions posted by participants.

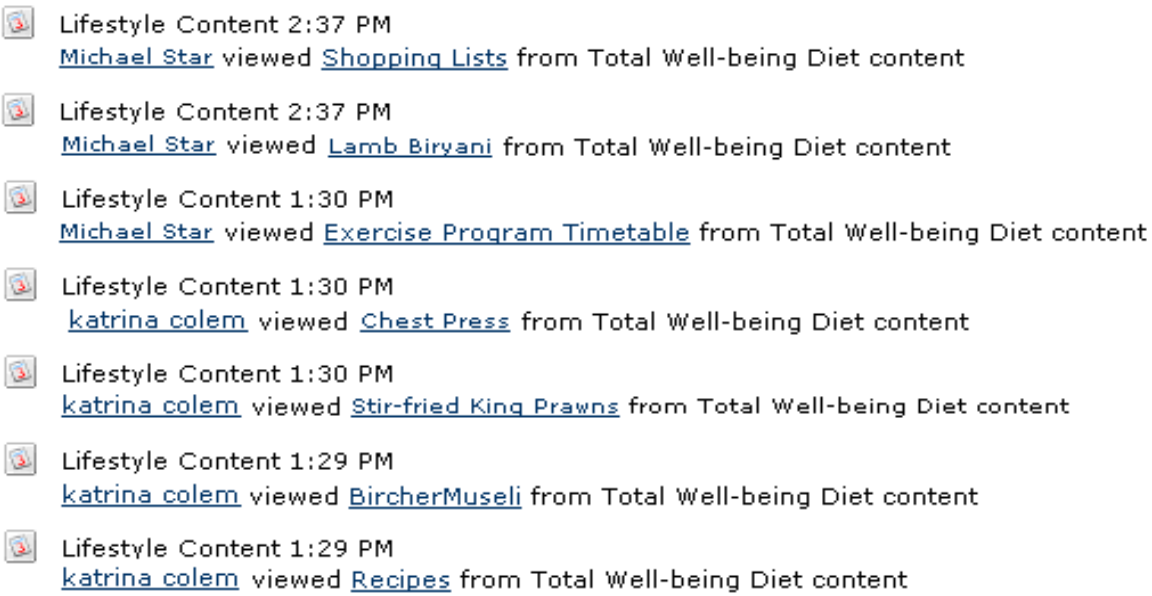

Figure 3. Sample feed segment 
The static educational component of SOFA consists of scientifically validated information on diet and lifestyle taken from the CSIRO's Total Well-being Diet book (Noakes \& Clifton, 2005) and quizzes taken from the Better Health Channel ${ }^{10}$. It covers information on the TWD diet, 160 recipes, 22 exercises, 12week menu plans and shopping lists, alcohol management recommendations, 24 success stories, 16 quizzes, and other health-related links.

The content was segmented into chapters as per the book layout: diet details, recipes, menu plans, exercise plan, shopping lists, and success stories, and linked using a tree structure for ease of navigation as shown in Figure 4. By clicking on each section, the users were taken to a separate page broken into sub-sections. For example, the recipe page was broken into Breakfast \& Brunch, Soups \& Salads, Seafood, Chicken \& Pork, Beef and Veal, Lamp, Vegetables and Desserts.

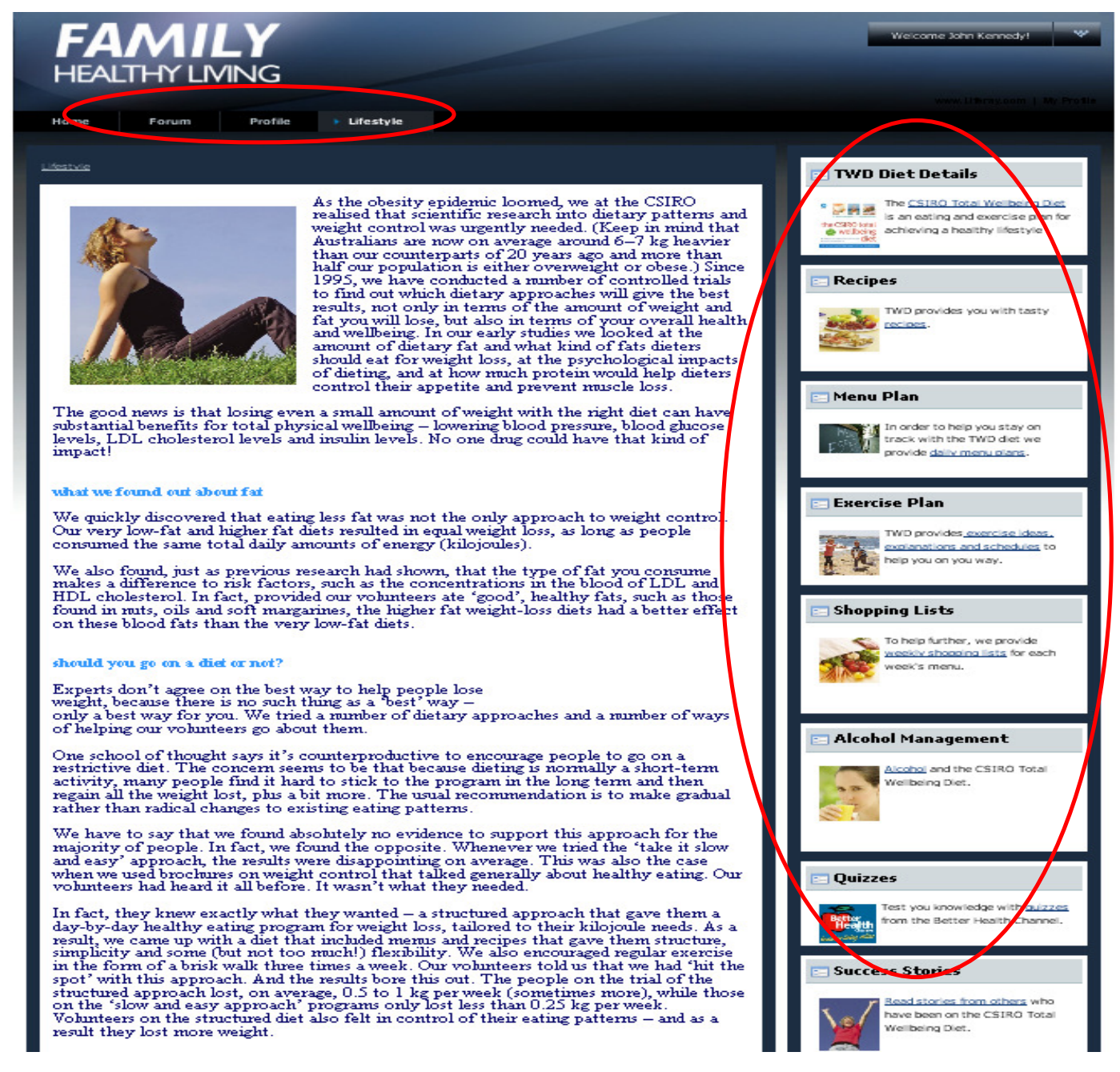

Figure 4. SOFA content.

SOFA implemented three persuasive features described in section 2: social learning, normative influence and self-expression. Social learning was supported through the activity feed (Figure 3) that allowed users

10 http://www.betterhealth.vic.gov.au 
to observe actions of other users, such as reading health-related content, submitting quizzes, posting messages to forum and blogs, writing on each others' walls, updating profiles, etc. By exposing the actions, people were made aware of the experiences of others on a journey similar to theirs. Normative influence was supported by recruiting families, who were interested in adopting a healthy lifestyle and facilitating their interactions in the forum and blogs. Self-expression was supported through the user profiles and blogs, as the users were able to express themselves online by contributing content to their profile and to be observed by others on the network.

To investigate the effect of system-defined tasks on user engagement, we integrated a task panel, which displayed a list of weekly tasks to users. Each task specification was hyperlinked to the area of the site where this task could be completed. In particular, families were asked to update their profile, input their daily activities in the activity diary, write about their thoughts and feelings in the blog, ask questions and share information on the forum, view users' activities, and read the heath-related resources. The tasks were updated on a weekly basis. In the shared family profile representation, only one member was required to update a profile, but all the other tasks could be done by each individual member. A sample set of tasks is shown below:

- Update your profile by adding hobbies

- Put down what you eat for lunch everyday this week

- How are you feeling this week? Would you like to add it to your blog?

- Consider doing two quizzes

- Did you know that SOFA has a forum? You might like to visit the forum and post a message

- Visit the content section of SOFA and find three interesting recipes for you and your family

- You may consider sharing a recipe you read, on the forum or your blog

SOFA was implemented using Liferay Enterprise Portal ${ }^{11}$, which is an open source Java-based portal technology that supports many social networking features. All the users' interactions were stored in an Oracle database.

\section{Live User Study}

\subsection{EXPERIMENTAL SETUP}

A three week live user evaluation on the SOFA was carried out in July of 2009. Recruitment was achieved through print media and a market recruitment company. Participants were required to have basic knowledge of computers and internet and have previously used social networks/online communities or be familiar with how they work. We recruited a cohort of nuclear families, consisting of two parents and two children aged between 10 and 17, all residing in one household. This age group was chosen because such children predominantly live with their parents, and are usually familiar with Internet technologies.

To investigate the effects of family-based and individual profile representations, we created two conditions: individual and family. Families assigned to the individual condition were supplied with 4 individual user profiles, whereas families in the family condition were represented by a single family profile, thus each family rather than each individual, was represented on the network. To investigate the effects of user tasks, we created two more conditions: individual+tasks and family+tasks. These are similar to the individual and family conditions, but in both conditions users were provided with a set of tasks aimed at increasing user engagement with SOFA. We broke the activities into contribution actions,

11 www.liferay.com 
which include submitting quizzes, adding to the activity diaries and posting forum, blog and wall messages and consumption actions, which were primarily viewing actions on the content and profiles of others.

In total, 96 families were invited to participate in the evaluation study and were randomly assigned to 4 experimental conditions of 24 families each. The average adult age was 41.4 and the average child age was 13.1. The number of participants who took up the invitation and participated in the trial, i.e., logged into SOFA at least once, is shown in Table 1.

\begin{tabular}{|c|c|c|}
\hline Conditions/ groups/ communities & \# Individuals partaking & \# families partaking \\
\hline individual & 38 & 16 \\
\hline family & 31 & 20 \\
\hline individual+tasks & 43 & 21 \\
\hline family+tasks & 27 & 16 \\
\hline
\end{tabular}

Table 1. Participant details.

It is worth noting that participants in each condition were segregated from each other and could see neither the profile pages nor forum content from other conditions. In effect we created 4 separate social networks. The segregation avoided inter-condition influences, e.g., users with individual profiles viewing familybased profiles and vice versa. However, as a result of this segregation, users were exposed to different network dynamics. We explain how we compensated for this in Section 4.3.

\subsection{METHODOLOGY}

Participants were asked to interact with the system on a regular basis over a period of 3 weeks. They completed pre and post task questionnaires and all interactions with the system were recorded. In order to bootstrap the social network, we created two fictitious users for each condition and uploaded a set of social content (initial forum posts, blogs, activities, and profiles) for each fake user uniformly across all the conditions. Email reminders were sent every five days to all participants and included some statistics on the usage of the website, e.g., the number of active participants, and some quotes the participants had left on the forum and blogs.

\subsection{EVALUATION METRICS}

The engagement of users with SOFA is the main dependent variable for our research questions. To measure user engagement, we used the approach proposed by Cheng and Vassileva (2005) and Farzan et al. (2009) which looks at the actions a user carries out and their importance to the sustainability of the system. Cheng and Vassileva deem important actions to be those which are likely to spark further engagement, that is, those that are likely to generate further contributions from others. Farzan et al. (2009) uses a similar justification but considers important actions as those which require user effort and work as they show that users were sufficiently engaged with the system to carry out the work required. Since posting forum messages requires explicit work and is likely to generate responses from other users we gave forum posting high weight. Similarly updating blog, activity diary and profile, writing on the walls and friending are also considered important, as they require work and may result in more engagement from other users (and the person, who provided the content in the first place), but they are not deemed as important as posting messages to group forum. Other actions are considered to be less important. SOFA users can perform 24 activities, shown in Table 2.

\begin{tabular}{|l|l|l|}
\hline $\boldsymbol{i}$ & Activities & $\mathbf{W}_{\mathbf{i}}$ \\
\hline 1 & Login & 1 \\
\hline
\end{tabular}




\begin{tabular}{|l|l|l|}
\hline $2,3,4,5,6,7,8$ & $\begin{array}{l}\text { View forum posts, blog entries, profile pages, } \\
\text { Homepages, images, image folder, Total Wellbeing } \\
\text { Diet content }\end{array}$ & 1 \\
\hline $9,10,11,12,13,14$ & $\begin{array}{l}\text { Image add, image update, image delete, image folder } \\
\text { add, image folder update, image folder delete }\end{array}$ & 1 \\
\hline 15 & Update profile & 2 \\
\hline 16 & Write blog entry & 2 \\
\hline 17 & Comment on a blog & 2 \\
\hline 18 & Complete quiz & 2 \\
\hline 19 & Update activity diary & 3 \\
\hline 20 & Save food preferences & 3 \\
\hline 21 & Save recipe preferences & 3 \\
\hline 22 & Write wall messages & 4 \\
\hline 23 & Add friends & 3 \\
\hline 24 & Write forum message & 3 \\
\hline & Table 2. Different weights for user activities. & \\
\hline
\end{tabular}

The activities are broken into consumption and contribution. Consumption score for each user is measured by adding all their viewing activities (i.e. activities $2,3,4,5,6,7 \& 8$ ) and contribution score is measured by adding the rest of the activities.

The number of times a user performs an activity $i$ is denoted by $F_{i}$. Since the importance of the activities varies, weights $W_{i}$ were introduced. In addition, a user's consumption and contribution scores and their engagement with the system are not only related to the items contributed or consumed by that user, but are also influenced by the size of their community $\left(N_{c}\right)$. For example, users in individual+task condition with 43 members would have had more actions happening in the network than users in family+task condition with 27 members. In an effort to reduce this effect of the community, we factored in the size of each community. An overall measurement of an individual's engagement " $V_{o e}$ " is, therefore, calculated using the following Formula:

$$
V o e=\left(\sum_{i=1}^{24} W_{i} * F_{i}\right) / N c
$$

It is worth mentioning that there are other ways of normalizing a community, for example by the amount of activities performed in that community. We noted that the number of activities performed in each community is correlated with the community size and that is why we normalized the scores by the community size.

In addition to contribution, consumption and engagement, we also looked at retention of the users and days active on the system. Retention is measured by calculating the percentage of users in each experimental condition that stayed with SOFA for a given number of days or more and days active is the number of days in the 3-week study that each user visited SOFA.

To measure change of users' attitude towards healthy living as a result of engaging with SOFA, we used the Health Locus of Control (HLOC) scale (Wallston K, Wallston \& DeVellis, 1978) as part of our pre and post task questionnaires. The scale includes 9 questions, which measure whether people feel their health is determined by external factors or by internal ones. 


\section{Results}

In this section we report on findings relating to the overall system use and particular activities of participants in the four experimental conditions.

\subsection{PROFILE REPRESENTATION \& TASK INCLUSION}

\subsubsection{User Interaction}

We hypothesised that profile representations and the presence of tasks would influence how users interacted with SOFA. Figure 5 shows the average contribution actions, consumption actions and engagement of the users across the experimental conditions. We clearly see that the average contribution actions of those represented as individuals (individual 0.51, individual+task 0.80) are significantly higher than those represented by families (family 0.26, family+task 0.49 ). This finding was verified using a twoway ANOVA $(F[1,138]=4.00, p<0.05)$. In both cases the contribution from those represented as individuals is approximately twice than that of their counterparts represented as family units. This suggests that the motivations to contribute are weakened when the family is represented as a unit. The presence of tasks did not significantly affect the rates at which users contributed to the site.

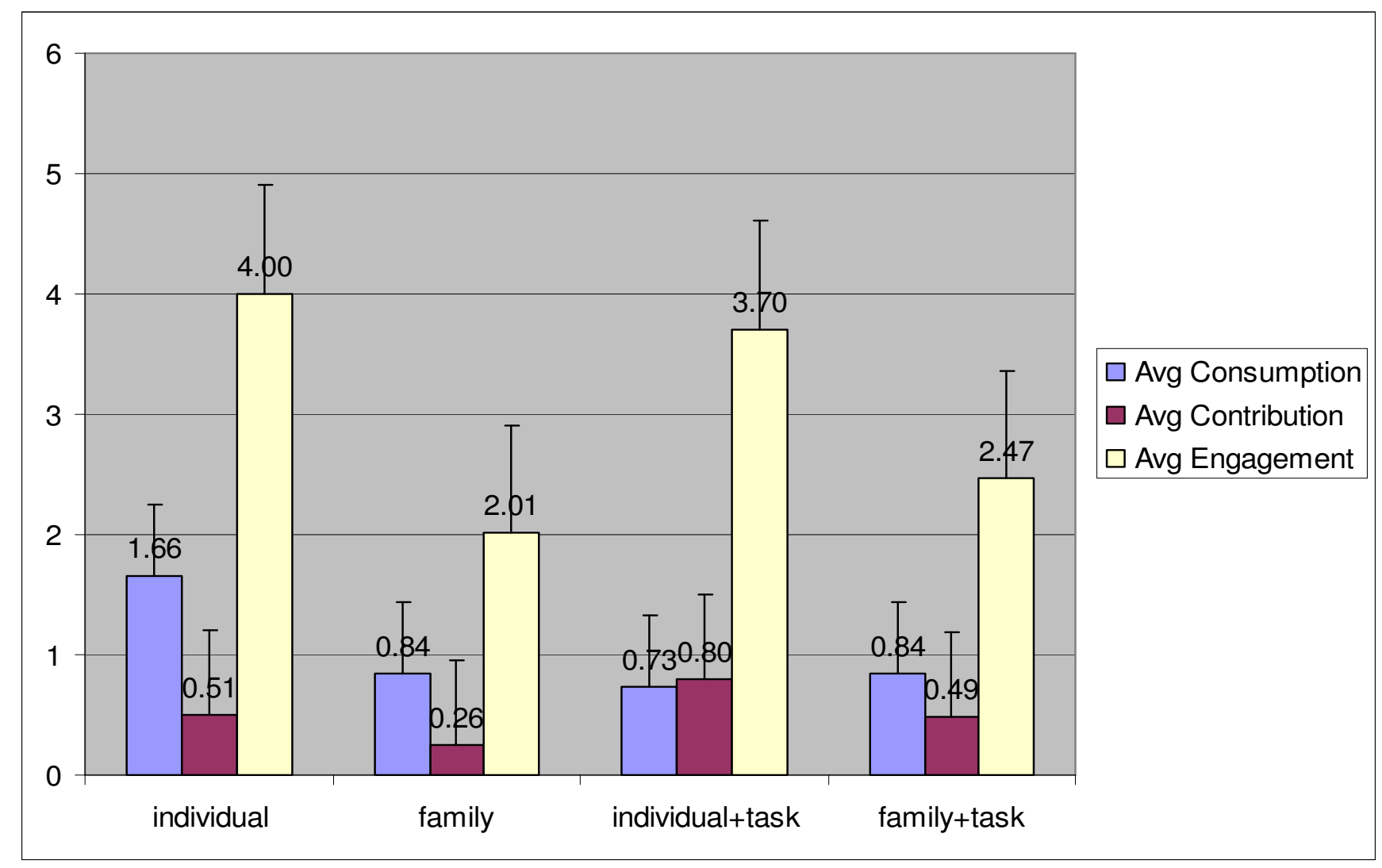

Figure 5. Average number of Consumption, Contribution \& Engagement

Users' rate of consumption of content was not on the whole affected by either profile representation or the presence of tasks. There was a borderline effect of providing tasks on consumption of the users in 
individual and individual+task conditions $(F[1,138]=3.96, p=.049)$. Users' overall engagement (weighted sum of contribution and consumption) was affected by profile representation. Users in individual profile representation were significantly more engaged with SOFA than those represented as family units $(F[1,138]=5.04, p<0.05)$. The presence of tasks did not have a significant effect on engagement.

We also looked at the percentage of families in each condition which had one, two, three and four active members (shown in Figure 6). We see similar distributions between the individual and individual+task conditions and again between the family and family+task conditions. Over $60 \%$ of families represented as family units had only 1 family member active, in comparison with approximately $40 \%$ of families represented as individuals. Similarly, in individual based representations, approximately $30 \%$ of families had all 4 family members active in comparison with approximately $10 \%$ of families represented as family units.

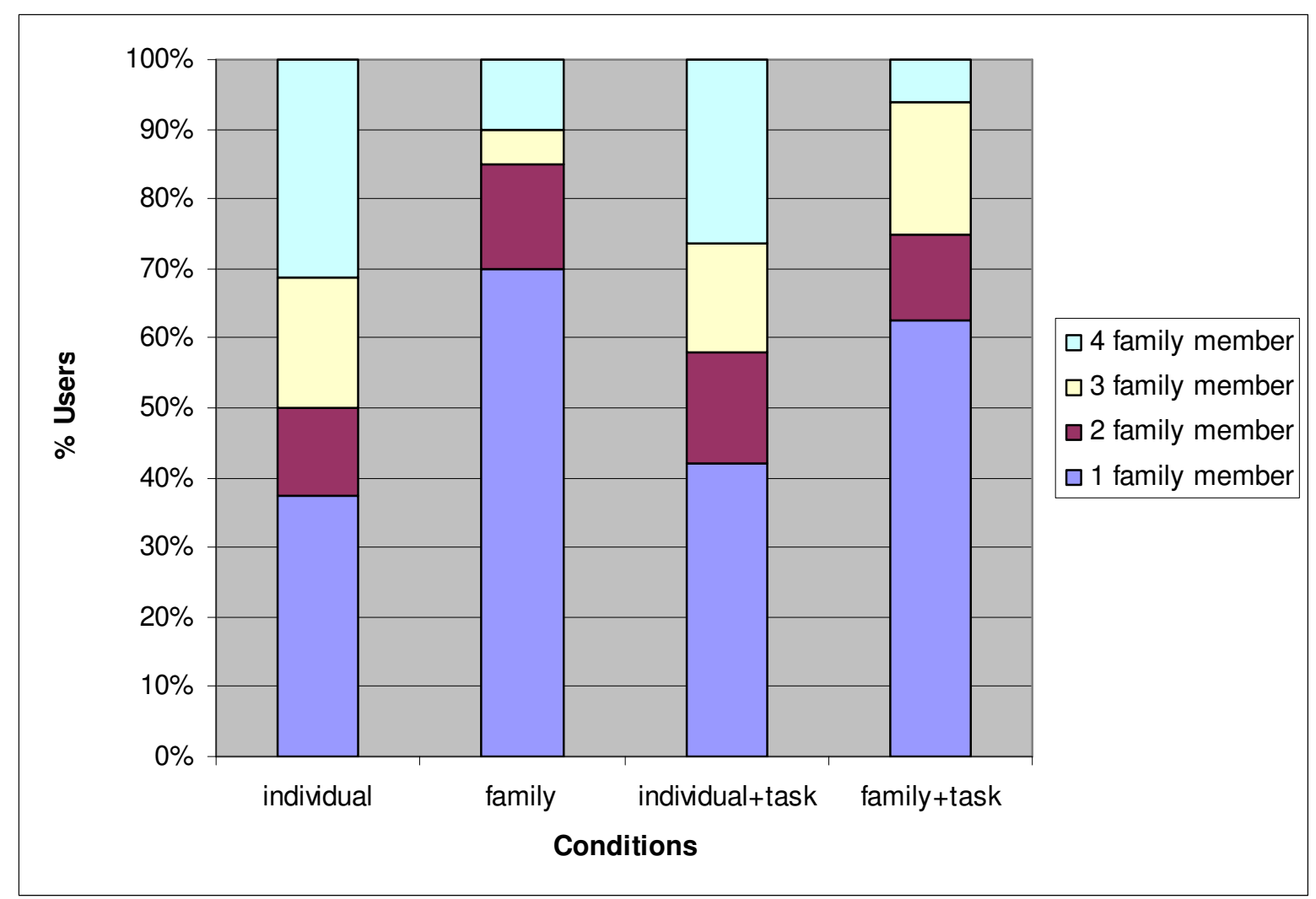

Figure 6. Percentage of active family members.

\subsubsection{User Retention}

In addition to what the users did and how much, we also examined their retention. Figure 7 shows the average number of days that individuals in each condition were active on SOFA. We clearly see that conditions individual and individual+task visited the site more often ( 7.21 days and 5.63 days respectively) than those represented by the family unit profiles (family 3.16 days, family+task 2.81 days). This finding was verified using a two-way $\operatorname{ANOVA}(F[1,138]=18.42, p<0.05)$. The presence of tasks did not have a significant effect on the number of days that an individual visited SOFA. 


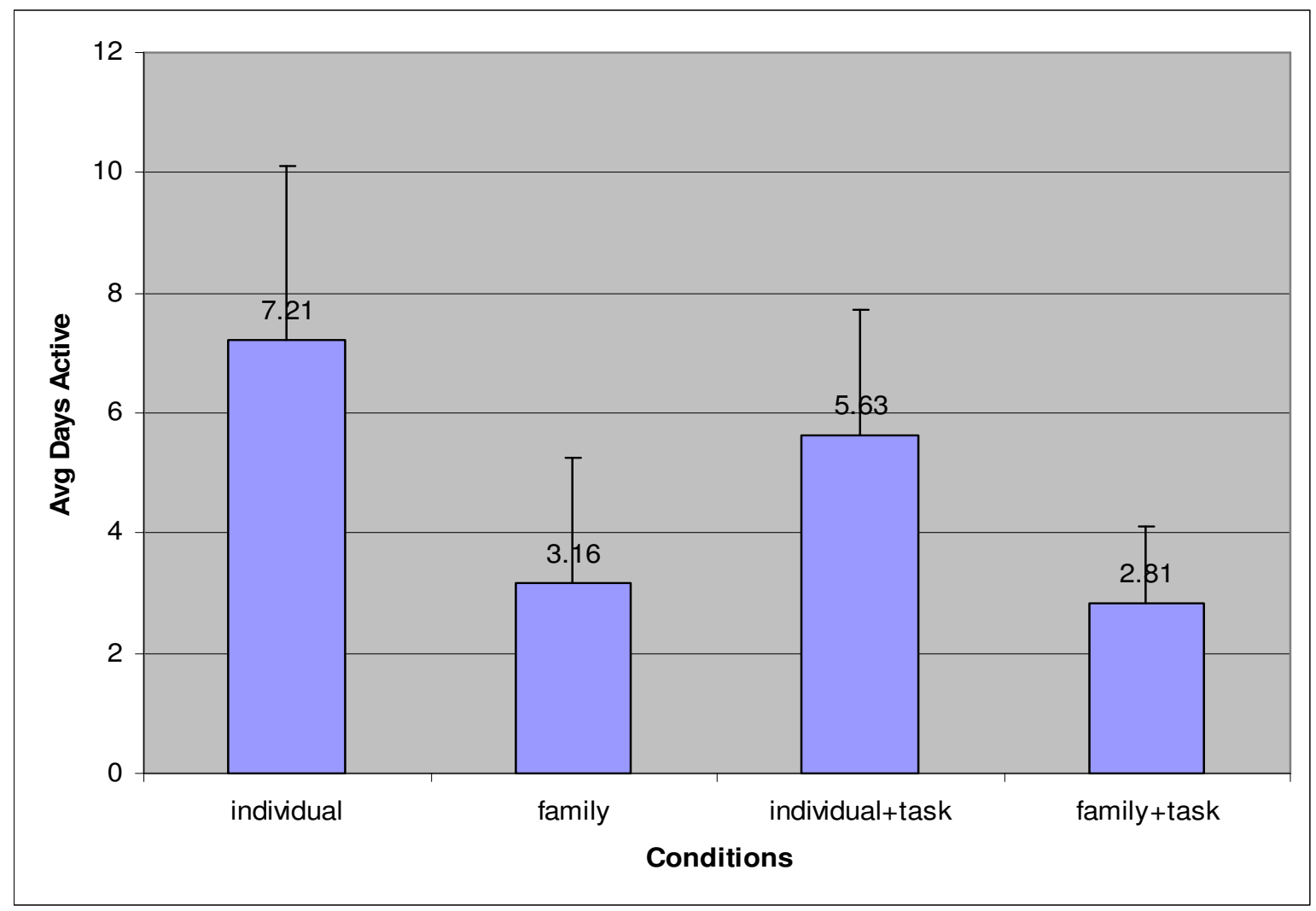

Figure 7. Average number of Days Active.

Figure 8 shows the percentage of all users in each experimental condition that stayed with SOFA for a given number of days or more. Across all four conditions the number of active users falls with the number of days. Initially, we see a very steep decline in the number of users as the day count increases, which is a common pattern observed in other social networking systems (Martin, 2009). The steepest decline is seen by the family+tasks condition, followed closely by the family condition. So, the family-based conditions lost members more rapidly than the individual conditions. The individual+task condition is comparable to the individual condition and the family+task is comparable to family condition. The individual condition is the stickiest condition with $24 \%$ of members returning after the second week, and a more gradual decline in numbers. After 21 days, the individual and individual+task conditions maintain more than twice as many users (6.3\% and $5.2 \%$ respectively) as the family-based conditions ( $2.1 \%$ and $1.0 \%$ respectively). This finding was verified using a two-way ANOVA $(F[1,138]=7.62, p<0.05)$. The average duration of those represented as individuals is significantly higher than that of users represented by families. The presence of tasks did not significantly affect the rates at which users returned to the site. 


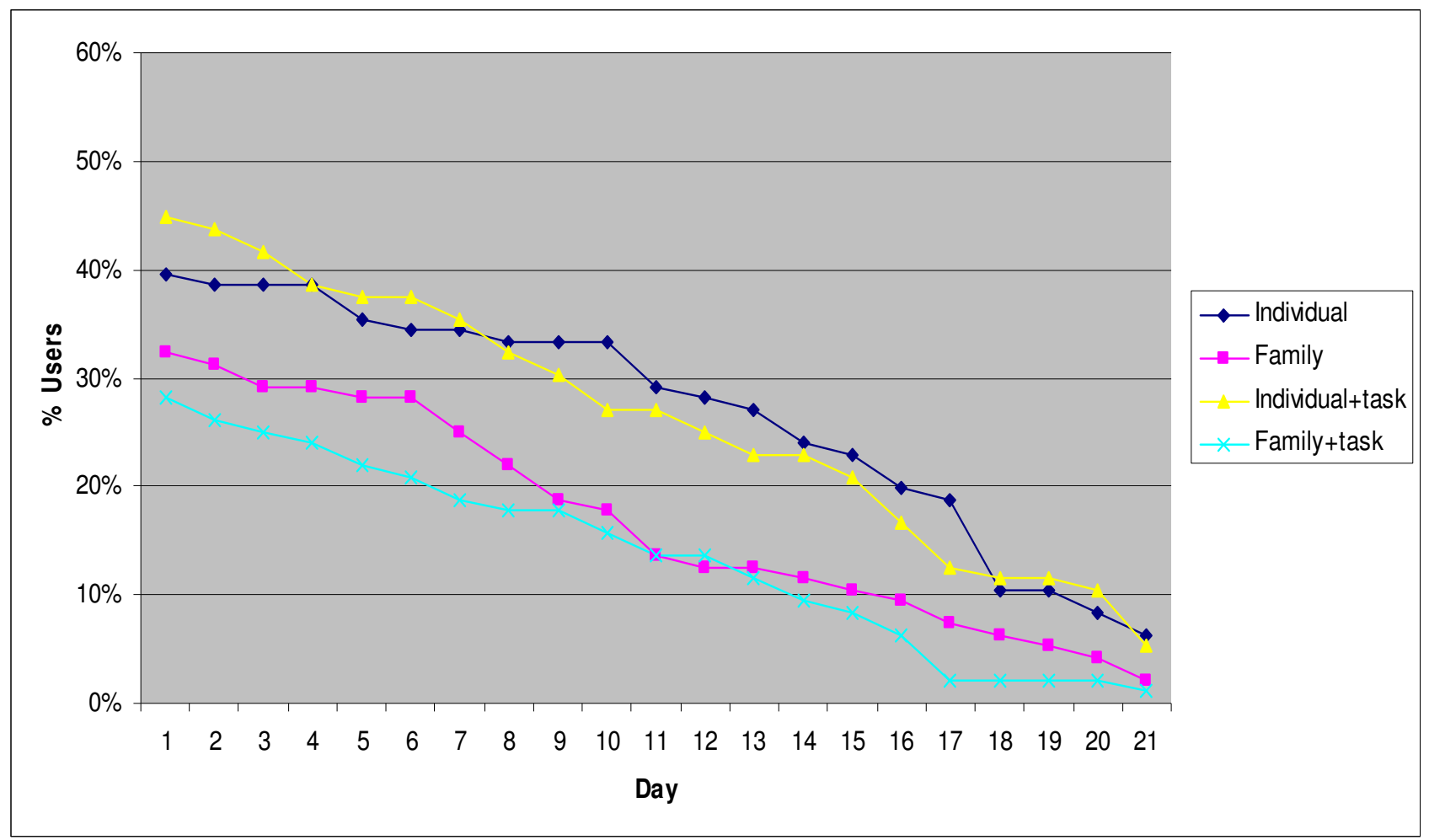

Figure 8. Retention rate for each condition.

\section{2. CHANGE IN ATTITUDE}

We were also interested in knowing whether high engagement with the health-related content through the social networking system would positively affect health-related behavior. Since the ability to change behaviour is limited in short time periods, we examined the effect of engagement with the system on users' change in attitude as an indicator of possible future behavioral change (Torning \& OinasKukkonen, 2009). Attitudes were measured using the shortened form of the Health Locus of Control (HLOC) scale (Bennett et al., 1995), which includes 9 items taken from the original MHLCQ (Wallston et al., 1978). This scale (Appendix 1) measured whether people feel their health is determined by external factors (chance (items $1,5,8$ ) or powerful others such as health-care workers (items 2,3,4)) or by internal factors (items 6, 7, 9). Summed scores for each construct range from 3 to 18 with higher scores indicating higher agreement that external factors (chance, powerful others) or internal factors determine health.

Change scores for each HLOC construct were calculated by subtracting baseline scores from follow-up scores. Table 3 presents mean change scores for those participants who completed both pre and post-task questionnaires.

\begin{tabular}{|c|c|c|c|}
\hline & M & SD & Range \\
\hline Chance & -.24 & 2.82 & -7.00 to 6 \\
\hline Internal & -.05 & 2.57 & -8.00 to 6 \\
\hline Powerful others & .15 & 3.15 & -7.00 to 7 \\
\hline
\end{tabular}

Table 3. Change in HLOC constructs $(n=95)$. 
We observed a significant correlation between the level of user engagement and feelings of chance, when the effect of the experimental conditions was controlled for $(F[1,94]=5.09, p<0.05)$. The unstandardised parameter was -0.23 indicating that for every increase in engagement group, there was a 0.23 decrease in change in the feeling that health was determined by chance. This finding indicates that reductions in the feeling that health is determined by external factors were related to increased user engagement (or vice versa). Engagement was not significantly associated with changes in the feeling that health is determined by internal factors.

In addition, our previous findings showed an increased interaction with a repository of health based information by coupling the repository with social networking features of SOFA (Freyne et al., 2010). We found that there was a high correlation (0.94) between the daily number of interactions on the social features and the number of interactions with the health-related content. This implied that the key to sustaining exposure to the content and increasing users' nutrition knowledge and change in attitude could lie in sustaining participation with the social network. The results also showed that coupling health-related content with a social networking system successfully increased content browsing by showing them the browsing actions of other users through social network activity feeds.

\subsection{SUBJECTIVE ANALYSIS}

We provided users with a post-evaluation questionnaire to ascertain their feedback on the site in general and on specific features included. Overall 58\% of users reported that SOFA was fun to use, $74 \%$ that it was an easy to use system, and $85 \%$ that the content was easy to access.

The positively received aspects of SOFA in descending order of popularity were the forum (69\%), presence of family members (64\%), the activity diary (52\%) and the blog features (37\%) with the least liked feature being the photo gallery $(7 \%)$. We were encouraged by users' high regard for the family inclusion offered by SOFA, with $64 \%$ of them listing the presence of their family members as one of the features they liked the most.

The aim of SOFA was to provide an access method allowing families to engage with healthy living information to promote healthy living. The questionnaire showed that the 3 week use of the system prompted $63 \%$ of respondents to have offline discussions on healthy living with family members. When asked in what aspects of their lives users noted a change as a result of using the system, $45 \%$ of users noted a change in diet, $40 \%$ in exercise and $40 \%$ adults reported a change in their smoking habits. The questionnaire also showed that more parents than children reported that: using SOFA resulted in a change of their perception towards healthy living, they learned more on healthy living from using SOFA, and they would recommend SOFA to other families. This suggests that parents remain conscious of and concerned about health issues (keen on learning, perception) even as they interact with social technology (Kimani et al., 2010). They often bear the primary responsibility of ensuring that their family is healthy.

An interesting point regarding user retention is some data gathered after the user trial completed. Due to several requests, the website remained available to all families and they were notified of this in the last reminder and through a statement at the front page of the website. In the 4 weeks from the study completion, 84 users from 40 families (60\% of the total number of families participating) logged in more than 300 times and continued interacting with the website.

\subsection{DISCUSSIONS}

The results show that individual profile representations significantly increase the user contribution, engagement, days active and retention with the system compared with a shared family profile representation. Furthermore, the results show that individual profile representation increases the chance of 
multiple family members participating. The user consumption, however, was comparable for both profile representations. The difference in consumption and contribution can be explained by how user profiles were implemented in SOFA. In the individual representation, each family member created and maintained their own identity and was seen on the network as an individual, hence his/her contribution was recognized and that might have encouraged them to keep coming back and contributing more. Our intuition for providing family-based profiles was that they would allow family members to participate without having to each create a profile representation, thus, lowering the boundary for entry for the remaining family members and resulting in an increased contribution. However, they provided a level of anonymity in that members within a family were not recognized for their individual contributions and their identities on the network were represented as a single shared profile rather than separate individuals. Hence they may not have been as motivated to contribute information as people in individual profile conditions were.

The results show that individual profile representation increases the chance of multiple family members participating and that the majority of families with only one active member were in the family based representations. This can be explained by theory of social loafing: "the tendency for individuals to expend less effort when working collectively than when working individually" (Karau \& Williams, 1993). The tendency of family members relying on one member has also been reported in a study by Kiesler et al. (2000), in which they found that family members would heavily rely one a member with comparatively high technical skill or enthusiasm to provide them with technical help when using the Internet and to make external technical support requests.

Overall the presence of tasks did not have any significant effect on increasing user contribution, consumption, engagement and days active on the system across the four experimental conditions. We hypothesised that users, who were encouraged to explore the system under guidance, may be spurred to do further exploration unguided and become more engaged with the system. However, the results revealed a similar pattern for consumption, contribution and engagement across the family profile representation and no significant difference in contribution for individual profile representation. The tasks were optional, with no rewards offered to users for their completion. With the inclusion of an incentive scheme, such as that implemented by Farzan et al. (2009), we may have seen different results. More studies are needed to examine the effect of providing tasks.

Overall, the relationships between the change of attitude and user engagement with SOFA were promising. External feelings of control (chance) indicated that increasing user engagement can have positive outcomes for Health Locus of Control constructs. There is some evidence that varying levels of the feeling that health is determined by chance interacts with feelings of internality to alter health behaviours (O'Hea et al., 2005). It is important that future research assesses how user engagement acts to alter changes in attitudes as changes in attitudes may be related to changes in health behaviour.

\section{Conclusions and Future Work}

This work aimed to exploit the popularity of social networking technologies in an attempt to impact the health of family members. The overall objective of our study was to explore the effect of providing both family and social support through an online social networking system on engagement with the system and change in attitude towards healthy lifestyle. Within the social network we were specifically interested in investigating the impact of two representations of family members, as individuals or as a family unit, and the presence of tasks. We proposed and described the design, implementation and evaluation of SOFA, a social networking system intended to engage and motivate families to adopt a healthy lifestyle. The contributions of this work were 1) proposing a novel approach to address both family support and social support in helping individuals to adopt a healthy lifestyle, 2) evaluating the effect of different profile 
representations and tasks on user engagement with the social layer and educational content and 3) evaluating the effect of providing a social layer on users' change of attitude towards healthy living.

We uncovered several interesting observations. The results show that individual profile representation increases the chance of multiple family members participating and results in significantly higher retention, contribution and engagement with the network. In addition, higher engagement with SOFA results in a significant change in users' attitude regarding the feelings of control over their health.

The practical plan for the SOFA system is to enhance it to reflect the outcomes learned from this study, including the content integration and profile representations. Given that more than half of the users listed the presence of their family members as one of the features they liked the most, we believe a balance must be made between preserving the family unit in order for people to include their families in their lifestyle change and encouraging participation from those included. Thus, we suggest that although in systems of this nature individual profiles should be the preferred representation, family member should be given the opportunity to openly associate themselves with other family members. These measures could include a family "friending" model, which associates family members differently to regular friends (e.g., allowing users to directly link their profiles to their family members'), family related feeds, etc.

Given the usability feedback and feature request from participants, we aim to refine the system and include additional functionalities. These functions fall into the broad categories of Content, Motivational Features and Social Features. Requests were made for supplementary content in the areas of exercise, diet and help features with calls for the addition of medical information relating to allergies, drug and medicine safety, and information specifically targeting children. The motivational content requested included personalised goal monitoring tools, tips, and inspirational ideas. Lastly the social features requested include the ability to rate the healthy lifestyle content, receive updates on family members' activity, interfamily competitions, gaming and the inclusion of an instant chat component.

The core research effort going forward will focus on effects on engagement and attitude changes as a result of personalisation technology in online social networks. We aim to focus on content recommendations, tailored menu plans, exercise schedule and customisation. In addition, we will look at the effect of providing social comparison on engagement level of the users at intra- and inter- family level. We also plan to conduct a longitudinal study on the effect of the system on participants' diet compliance, weight loss, and healthy living behavior.

\section{Acknowledgments}

This research is jointly funded by the Australian Government through the Intelligent Island Program and CSIRO Preventative Health Flagship. The Intelligent Island Program is administered by the Tasmanian Department of Economic Development, Tourism, and the Arts. We would like to thank Dipak Bhandari, Gilly Hendrie, Nathalie Colineau, Cecile Paris, Manny Noakes and Phil Mohr for their contribution to this research, and Holger Neuhaus for acting as our communication officer. We also acknowledge Penguin Group (Australia) and Better Health Channel for permission to use their data in our studies. 


\section{References}

Baghaei, N., Freyne, J., Kimani, S., Smith, G., Berkovsky, S., Bhandari, D., Colineau, N., Paris, C. (2009). SOFA: An Online Social Network for Engaging and Motivating Families to Adopt a Healthy Lifestyle. Proc. of 21st Annual Conference of the Australian Computer-Human Interaction Special Interest Group (CHISIG), 269272.

Bennett, P., Moore, L., Smith, A., Murphy, S., Smith, C. (1995). Health Locus of Control and Value for Health as Predictors of Dietary Behaviour. Psychology and Health, 10, 41-54.

Caverlee, J., Liu, L., Webb, S. (2008). SocialTrust: Tamper-Resilient Trust Establishment in Online Communities. Proc. of JCDL, 104-114.

Cheng, R., Vassileva, J. (2005). User Motivation and Persuasion Strategy for Peer-to-peer Communities. Proc. of HICSS'38, Hawaii, USA, 193-202.

Christakis, N.A., Fowler J.H. (2007). The Spread of Obesity in a Large Social Network over 32 Years. The New England Journal of Medicine, 357, 370-379.

Cohen, S. (2004). Social relationships and health. American Psychologist, 59, 676-684.

Colineau, N., Paris, C., Marendy, P., Bhandari, D., Shu, Y. (2009). Family Engagement in Weight Management. Proc. of CHI 2009-Extended Abstract.

DiMicco, J., Millen, D.R., Geyer, W, Dugan, C., Brownhotz, B., Muller, M.J. (2008). Motivations for Social Networking at Work. Proc of CSCW, 711-720.

Doherty, W.J. (2004). A Family-Focused Approach to Health Care. Wisconsin Family Impact Seminars.

Doherty, W.J., Campbell, T. (1998). Families and health. California: Sage Publications.

Facebook statistics. (2010). http://www.facebook.com/press/info.php?statistics

Farzan, R., DiMicco, J., Millen, D., Brownholtz, B, Geyer, W., Dugan, C. (2009). Results from Deploying a Participation Incentive Mechanism within the Enterprise. Proc. of the Conference on Human Factors in Computing Systems (CHI).

Fogg, BJ. (2003). Persuasive technology: Using Computers to Change What We Think and Do. San Francisco, California: Morgan Kaufmann Publishers.

Freyne, J., Berkovsky, S., Kimani, S., Baghaei, N., Brindal, E. (2010). Improving Health Information Access through Social Networking. Proc of International Symposium on Computer Based Medical Systems (CBMS). Perth, Australia.

Heimendinger, J., Uyeki, T., Andhara, A., Marshall, J.A., Scarbro, S., Belansky, E. and Crane, L. (2007). Coaching Process Outcomes of a Family Visit Nutrition and Physical Activity Intervention. Health Education \& Behavior,34(1).

Hutchinson, H., Mackay, W.E., Westerlund, B., Bederson, B.B., Druin, A., Plaisant, C., Beaudouin-Lafon, M., Conversy, S., Evans, H., Hansen, H., Roussel, N. and Eiderbäck, B. (2003). Technology probes: inspiring design for and with families. Proc. of the Conference on Human Factors in Computing Systems (CHI), $17-24$.

Jones, D., Beach, S. Jackson, H. (2004). Family influences on Health: A framework to organize research and guide intervention. Handbook of Family Communication. Lawrence Erlbaum Assoc., Mahwah NJ, 647—672.

Karau, S. J., Williams, K. D. (1993). Social loafing: A Meta-analytic review and Theoretical Integration. Journal of Personality \& Social Psychology, 65(4), 681-706.

Kiesler, S., Zdaniuk, B., Lundmark, V., Kraut, R. (2000). Troubles With the Internet: The Dynamics of Help at Home. International Journal of Human-Computer Interaction, 15(4), 323-351.

Kimani, S., Baghaei, N., Freyne, J., Berkovsky, S., Bhandari, D., Smith, G. (2010). Gender and Role Differences in Family-Based Healthy Living Networks, Proc. of the Conference on Human Factors in Computing Systems (CHI), 4219-4224.

Leimeister, J.M., Krcmar, H. (2005). Evaluation of a Systematic Design for a Virtual Patient Community. Journal of Computer-Mediated Communication. 10(4).

Leslie, E., Marshall, A.L., Owen, N., Bauman, A. (2005). Engagement and retention of participants in a physical activity website. Preventive Medicine, 40 (1), 54-59. 
Locke, E. A., Latham, G. P. (2002). Building a Practically Useful Theory of Goal Setting and Task Motivation. American Psychologist, 57(9), 705-717.

Martin, D. Twitter Quitters Post Roadblock to Long-Term Growth. http://blog.nielsen.com/nielsenwire/online mobile/twitter-quitters-post-roadblock-to-long-term-growth/, April 2009.

McCown, F., Nelson, M.L. (2009). What Happens When Facebook is Gone? Proc. of JCDL, 251-254.

McLean N., Griffin S., Toney K., Hardeman W. (2003). Family involvement in weight control, weight maintenance and weight-loss interventions: a systematic review of randomised trials. International Journal of Obesity, 27(9), 987-1005.

Noakes, M., Clifton, P. (2005). The CSIRO Total Wellbeing Diet. Australia: Penguin.

O'Hea, E. L., Grothe, K. B., Bodenlos, J. S., Boudreaux, E. D., White, M. A., Brantley, P. J. (2005). Predicting medical regimen adherence: The interactions of health locus of control beliefs. Journal of Health Psychology, 10(5), $705-717$.

Oinas-Kukkonen, H., Harjumaa, M. (2008). A Systematic Framework for Designing and Evaluating Persuasive Systems. Proc. of PERSUASIVE.

Ploderer, B., Howard, S., Thomas, P., Reitberger, W. (2008). Hey World, Take a Look at Me!: Appreciating the Human Body on Social Network Sites. Proc. of PERSUASIVE, 245-248.

Randell, R., Wilson, S., Fitzpatrick, G. (2010). Evaluating New Interactions in Health Care: Challenges and Approaches. International Journal of Human-Computer Interaction, 26(5), 407-413.

Rogers, Y., Lim, Y., Hazlewood, W. R., Marshall, P. (2009). Equal Opportunities: Do Shareable Interfaces Promote More Group Participation Than Single User Displays? International Journal of Human-Computer Interaction, 24(1), 79-116.

Rosenfeld, E. (2008). How to Build a Persuasive Web Application: Three Fundamental Feedback Loops. Proc. of PERSUASIVE, 241-244.

Torning, K., Oinas-Kukkonen, H. (2009). Persuasive System Design: State of the Art and Future Directions, Proc. of PERSUASIVE 2009.

Utz, S. (2010). Show me your friends and I will tell you what type of person you are: How one's profile, number of friends, and type of friends influence impression formation on social network sites, Journal of ComputerMediated Communication. 15, 314-335.

Wallston K, Wallston B, DeVellis R. (1978). Development of the Multi-dimensional Health Locus of Control. Health Education Monographs, 6, 160-170.

Weiksner, M., Fogg, BJ., Liu, X. (2008). Six Patterns for Persuasion in Online Social Networks. Proc. of PERSUASIVE, 151-163. 


\section{APPENDIX 1: Attitude Measurement Scale}

To what extent do you agree or disagree with the following statements?

\begin{tabular}{|c|c|c|c|c|c|c|c|}
\hline & Statements & $\begin{array}{l}\text { Strongly } \\
\text { disagree }\end{array}$ & $\begin{array}{l}\text { Moderately } \\
\text { disagree }\end{array}$ & $\begin{array}{l}\text { Slightly } \\
\text { disagree }\end{array}$ & $\begin{array}{l}\text { Slightly } \\
\text { agree }\end{array}$ & $\begin{array}{l}\text { Moderately } \\
\text { agree }\end{array}$ & $\begin{array}{l}\text { Strongly } \\
\text { agree }\end{array}$ \\
\hline 1 & $\begin{array}{l}\text { No matter what I do, if I } \\
\text { am going to get sick, I } \\
\text { will get sick }\end{array}$ & & & & & & \\
\hline 2 & $\begin{array}{l}\text { Having regular contact } \\
\text { with my doctor is the } \\
\text { best way for me to } \\
\text { avoid illness }\end{array}$ & & & & & & \\
\hline 3 & $\begin{array}{l}\text { Whenever I don't feel } \\
\text { well, I should consult a } \\
\text { medically trained } \\
\text { professional }\end{array}$ & & & & & & \\
\hline 4 & $\begin{array}{l}\text { Health professionals } \\
\text { control my health }\end{array}$ & & & & & & \\
\hline 5 & $\begin{array}{l}\text { My good health is } \\
\text { largely a matter of good } \\
\text { fortune }\end{array}$ & & & & & & \\
\hline 6 & $\begin{array}{l}\text { The main thing which } \\
\text { affects my health is } \\
\text { what I do myself }\end{array}$ & & & & & & \\
\hline 7 & $\begin{array}{l}\text { If I take care of myself, } \\
\text { I can avoid illness }\end{array}$ & & & & & & \\
\hline 8 & $\begin{array}{l}\text { If it's meant to be, I will } \\
\text { stay healthy }\end{array}$ & & & & & & \\
\hline 9 & 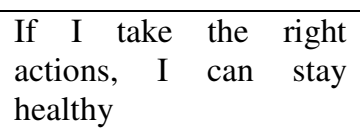 & & & & & & \\
\hline
\end{tabular}

